УКД 159.9

DOI: $10.24045 / a p s .2017 .1 .2$

СОВРЕМЕННЫЕ ПРЕДСТАВЛЕНИЯ О СОДЕРЖАНИИ ПОНЯТИЯ ПОЗНАВАТЕЛЬНАЯ СФЕРА МЛАДШИХ ШКОЛЬНИКОВ В ОТЕЧЕСТВЕННОЙ ПСИХОЛОГИИ

А. И. Ходина

\author{
Магистрант \\ Самарский государственный \\ соииально-педагогический университет \\ 2. Самара, Россия
}

\title{
MODERN IDEAS ABOUT THE CONTENT OF THE CONCEPT OF INFORMATIVE SPHERE OF YOUNGER SCHOOLBOYS IN THE NATIONAL PSYCHOLOGY
}

A. I. Khodina
Undergraduate student

Samara State Social Pedagogical University

Samara, Russia

\begin{abstract}
This article reviews the psychological literature of Russian authors on the content of the concept of informative sphere of younger school. The analysis suggests that the cognitive sphere is an aggregate of various forms and levels of cognitive processes, cognitive ability and cognitive activity.
\end{abstract}

Keywords: cognitive sphere; younger school age; sensation; perception; attention; memory; thinking; imagination; speech; cognitive activity; cognitive processes; cognitive abilities.

Младший школьный возраст представляет собой период активного развития и формирования познавательных способностей ребенка. Именно в этом возрасте у ребенка развиваются формы мышления, обеспечивающие в дальнейшем усвоение системы научных знаний и развитие научного, теоретического мышления, закладываются фундамент умения учиться и предпосылки самостоятельной ориентации в учении, окружающем мире, формируются исследовательские умения.

Познавательная сфера - это целостная, системно организованная совокупность различных форм и уровней познавательных процессов, познавательных способностей и познавательной деятельности, обеспечивающая продуктивность познания и преобразования человеком мира и самого себя.

Под познавательным развитием личности А. Г. Асмолов понимает формирование у учащихся научной картины мира, развитие способности управлять своей познавательной и интеллектуальной деятельностью, овладение методологией познания, стратегиями и способами познания и учения, развитие репрезентативного, символического, логического и творческого мышления, продуктив- 
ного воображения, произвольных памяти и внимания, рефлексии [6].

В. Н. Дружинин в свою очередь отмечает, что познавательная деятельность, как совокупность познавательных умений и навыков, связана с получаемыми знаниями и способами их приобретения, состоит из познавательных процессов и опирается на ощущения, восприятие, внимание, память, мышление, воображение. Приобретаемые познавательные способности - это тот потенциал человека, который составляет его психическое развитие [1].

Обратимся к структуре познавательной деятельности. Она осуществляется посредством гностических действий, которые, как отмечает П. А. Сорокун, делятся на два класса: внешние и внутренние [5].

Внешние гностические действия направлены на познание предметов и явлений, которые непосредственно действуют на органы чувств. Эти действия осуществляются в процессе взаимодействия органов чувств с внешними объектами.

Внешние гностические действия, совершаемые органами чувств, могут быть поисковыми, установочными, фиксирующими и прослеживающими. Поисковые действия направлены на обнаружения объекта познания, установочные - на выделение его среди других объектов, фиксирующие - на обнаружение наиболее характерных его свойств и качеств, прослеживающие - на получение информации о тех изменениях, которые происходят в объекте. Продуктом этих действий являются сенсорные познавательные процессы - ощущения и восприя- тия, которые отражают состояние внешней и внутренней среды и отдельные объекты.

Результатом познавательной деятельности на чувственной ступени познания являются субъективные впечатления и образы, которые отражают предметы и их свойства как при непосредственном контакте, так и на расстоянии. Возникновение субъективных впечатлений и образов осуществляется на основе сенсорных и перцептивных действий, направленных на обнаружение, различение, отождествление и опознание предметов и их свойств.

Впечатления и образы, возникающие на чувственной ступени познания, являются основой для осуществления внутренних гностических действий, на основе которых проявляются интеллектуальные процессы: память, воображение и мышление [5].

Между сенсорными и интеллектуальными процессами существует постоянная связь. Содержание сенсорных познавательных процессов является материалом для функционирования интеллектуальных процессов, а последние, в свою очередь, делают их осмысленными и понятными для личности. Все это происходит потому, что познавательная деятельность человека осуществляется в рамках сознания, которое интегрирует их в единый процесс познания.

Объединение всех элементов познавательной деятельности в единое целое осуществляет также язык и речь, на базе которых функционирует сознание, и благодаря чему человек не только осознает окружаю- 
щий его мир и самого себя, но и в состоянии регулировать свою познавательную деятельность [5].

Также большую роль в процессе познания играет внимание. Оно направляет и сосредотачивает сознание человека на познаваемых предметах и явлениях. Внимание, как замечает О. В. Ерусева, считается одним из тех психических состояний человека, которое обеспечивает продуктивное функционирование всех психических познавательных процессов [2].

П. А. Сорокун отмечает, что познавательная деятельность связана не только с познавательными, но и с волевыми процессами. Так, воля осуществляет регулирующую функцию, она мобилизует все ресурсы на преодоление трудностей, возникающих в процессе познания.

Познавательная

деятельность неразрывно связана с чувствами и эмоциями, так как человеку свойственно переживание своего отношения к тому, что он познает или делает. В связи с этим все познавательные процессы приобретают эмоциональную окраску или, так называемый, чувственный тон. Особенно это ярко проявляется в ощущениях и восприятиях. Чувства влияют и на продуктивность памяти.

Большое влияние оказывают чувства и на процесс мышления. Возникающие в процессе мышления трудности иногда оказывают негативное или позитивное влияние на интеллектуальную деятельность.

Большое влияние на результаты познавательной деятельности человека оказывают познавательные способности. Их наличие дает воз- можность успешно изучать и исследовать предметы и явления, приобретать новые знания, решать проблемные задачи, применять новые приемы и способы умственной деятельности. Познавательные способности могут быть сенсорными, перцептивными, мнемическими, репродуктивными, интеллектуальными и вербальными.

Познавательные способности стимулируют, направляют и регулируют гностическую деятельность, делая ее более продуктивной, чем при их отсутствии.

Сенсорные способности дают возможность более полно и точно отражать свойства и качества предметов и явлений, а также состояний внешней и внутренней среды.

Перцептивные способности проявляются в умении наблюдать за предметами и явлениями, замечать малейшие изменения в их состоянии и развитии.

Мнемические способности обеспечивают полное и точное запоминание, сохранение и воспроизведение полученной в процессе познания информации.

Репродуктивные способности помогают представить внутреннее строение и структуру изучаемых объектов и те изменения, которые могут произойти с ними в будущем.

Интеллектуальные способности проявляются в умении анализировать и обобщать полученную в процессе познания информацию, и оперировать образами и мыслями, делать правильные теоретические и практические выводы.

Вербальные способности дают возможность правильно описать по- 
знаваемые предметы и явления, подвести итоги познавательной деятельности, правильно сформулировать гипотезы, концепции и теории, объясняющие сущность изучаемых явлений [5].

Ведущим видом деятельности для младшего школьника является учебная деятельность, которая в начальных классах стимулирует прежде всего развитие психических процессов непосредственного познания окружающего мира - ощущений и восприятий [7].

Происходит переход от непроизвольного восприятия ребенка дошкольника к целенаправленному произвольному наблюдению за объектом, подчиняющемуся определенной задачи.

О. В. Ерусева отмечает общеизвестность остроты и свежести восприятия школьника в данный период, его любознательность, присущую ему яркость воображения.

Внимание его уже относительно длительно и устойчиво, и это отчетливо проявляется в играх, в занятиях рисованием, лепкой, элементарным конструированием. Ребенок уже имеет некоторый опыт управления своим вниманием, самостоятельной его организацией [2]. Однако возможности волевого регулирования внимания ограничены. Помимо этого, произвольное внимание младшего школьника требует короткой, или близкой мотивации [7].

Значительно лучше в этом возрасте развито непроизвольное внимание. Обучение оказывает стимулирующую функцию на его развитие, когда все новое, неожиданное, яркое, интересное привлекает вни- мание учеников само собой, без всяких усилий с их стороны.

Возрастной особенностью рассматриваемого познавательного процесса является и его сравнительно небольшая устойчивость. Неустойчивость внимания младших школьников является следствием возрастной слабости тормозного процесса. Это в основном характеризует учеников 1 и 2 классов и означает, что они не умеют длительно сосредоточиваться на работе, их внимание легко отвлекается [2].

Перейдем к рассмотрению следующего познавательного процесса - памяти. И. А. Шаршов указывает, что у ребенка младшего школьного возраста преобладает непроизвольный вид памяти, при котором отсутствует сознательно поставленная цель. В этот период сохраняется зависимость запоминания материала от таких его особенностей, как эмоциональная привлекательность, яркость, прерывистость действия, движение, контраст и т. д. Если предметы, с которыми встречается ребенок, называются, то он запоминает их лучше, что говорит о существенной роли слова.

Данная характеристика получает свое развитие под влиянием обучения в двух направлениях - усиливается роль и удельный вес словеснологического, смыслового запоминания (по сравнению с нагляднообразным), и ребенок овладевает возможностью сознательно управлять своей памятью и регулировать ее проявления (запоминание, воспроизведение, припоминание). Память приобретает ярко выраженный познавательный характер [7]. 
Изменения в области памяти связаны с тем, что ребенок, во-первых, начинает осознавать особую мнемическую задачу, он отделяет эту задачу от всякой другой. Вовторых, в младшем школьном возрасте идет интенсивное формирование приемов запоминания, учащиеся активно усваивают различные стратегии и техники, которые называются процессами контроля [3].

Ребенок уже знает из опыта: для того, чтобы хорошо запомнить нечто, надо несколько раз повторить это, т. е. эмпирически овладевает некоторыми приемами рационального запоминания и заучивания. Относительно хорошо развита у ребенка наглядно-образная память, но имеются уже все предпосылки для развития и словесно-логической памяти. Повышается эффективность осмысленного запоминания [7].

Основная тенденция развития воображения в младшем школьном возрасте - это совершенствование воссоздающего воображения, которое связано с представлением ранее воспринятого или созданием образов в соответствии с данным описанием, схемой, рисунком. Воссоздающее воображение совершенствуется за счёт всё более правильного и полного отражения действительности.

При развитии у ребенка способности управлять своей умственной деятельностью воображение становится все более управляемым процессом, и образы возникают в русле задач, которые ставит содержание учебной деятельности [4].

Что касается речи ребенка, то она уже довольно развита и в известной степени грамматически правильна, выразительна [7]. По мере того как продолжает расширяться их словарный запас, младшие школьники овладевают все более сложными грамматическими структурами и более тонким словоупотреблением [3].

Л. С. Выготский выделял главным новообразованием младшего школьного возраста мышление, которое приобретает абстрактный и обобщенный характер. Ребенок начинает обучаться в школе, обладая конкретным мышлением. Под влиянием обучения происходит постепенный переход от познания внешней стороны явлений к познанию их сущности, отражению в мышлении существенных свойств и признаков. В школе за относительно короткий промежуток времени ребенок должен овладеть системой научных понятий, в этом процессе должна быть задействована не только память, от ребенка требуется развитие мыслительных операций. В процессе школьного обучения происходит не только усвоение отдельных знаний и умений, но и их обобщение и вместе с тем формирование интеллектуальных операций [7].

Таким образом, младшие школьники обладают большими резервами развития, в том числе познавательной сферы. Учебная деятельность способствует началу перестройки всех его познавательных процессов, развитие которых характеризуется тем, что из действий непроизвольных, совершающихся непреднамеренно в контексте игровой или практической деятельности, они превращаются в самостоятельные виды психической деятельности, 
имеющие свою цель, мотив и способы выполнения.

\section{Библиографический список}

1. Дружинин В. Н. Психология общих способностей. - СПб. : Питер, 1999. $368 \mathrm{c}$.

2. Ерусева О. В. Роль внимания в развитии познавательных процессов // Научные исследования в образовании. - 2009. - № 1. - С. 1-5.

3. Крайг Г., Бокум Д. Психология развития / науч. ред. пер. на рус. яз. Т. В. Прохоренко. - СПб. : Питер, 2010. $940 \mathrm{c.}$.

4. Кулагина И. Ю., Колюцкий В. Н. Возрастная психология: развитие человека от рождения до поздней зрелости : учеб. пособие. - М. : Сфера, 2009. $464 \mathrm{c.}$

5. Сорокун П. А. Основы психологии. Псков : ПГПУ, 2005. - 312 с.

6. Формирование универсальных учебных действий в основной школе: от действия к мысли. Система заданий: пособие для учителя / А. Г. Асмолов, Г. В. Бурменская, И. А. Володарская; под ред. А. Г. Асмолова. - М. : Просвещение, 2010. - 159 с.

7. Шаршов И. А., Субботкина М. И. Возрастные особенности младшего школьника в контексте формирования уни- версальных учебных действий // Вестник ТГУ. 2012. Вып. 12. С. 181-185.

\section{Bibliograficheskij spisok}

1. Druzhinin V. N. Psihologija obshhih sposobnostej. - SPb. : Piter, 1999. - 368 s.

2. Eruseva O. V. Rol' vnimanija $v$ razvitii poznavatel'nyh processov // Nauchnye issledovanija v obrazovanii. - 2009. № 1. - S. 1-5.

3. Krajg G., Bokum D. Psihologija razvitija / nauch. red. per. na rus. jaz. T. V. Prohorenko. - SPb. : Piter, 2010. - 940 s.

4. Kulagina I. Ju., Koljuckij V. N. Vozrastnaja psihologija: razvitie cheloveka ot rozhdenija do pozdnej zrelosti : ucheb. posobie. - M. : Sfera, 2009. - 464 s.

5. Sorokun P. A. Osnovy psihologii. Pskov : PGPU, 2005. - $312 \mathrm{~s}$.

6. Formirovanie universal'nyh uchebnyh dejstvij v osnovnoj shkole: ot dejstvija $\mathrm{k}$ mysli. Sistema zadanij: posobie dlja uchitelja / A. G. Asmolov, G. V. Burmenskaja, I. A. Volodarskaja; pod red. A. G. Asmolova. - M. : Prosveshhenie, 2010. - $159 \mathrm{~s}$.

7. Sharshov I. A., Subbotkina M. I. Vozrastnye osobennosti mladshego shkol'nika v kontekste formirovanija universal'nyh uchebnyh dejstvij // Vestnik TGU. 2012. Vyp. 12. S. 181-185.

(C) Ходина А. И., 2017. 